\title{
Strengthening financial sustainability through integration of voluntary counseling and testing services with other reproductive health services
}

Rumeli Das

Kaushik Biswas

Pradeep Panda

M.E. Khan

Population Council

Rick Homan

Follow this and additional works at: https://knowledgecommons.popcouncil.org/departments_sbsr-rh

Part of the Demography, Population, and Ecology Commons, International Public Health Commons, Maternal and Child Health Commons, and the Public Health Education and Promotion Commons How does access to this work benefit you? Let us know!

\section{Recommended Citation}

Das, Rumeli, Kaushik Biswas, Pradeep Panda, M.E. Khan, and Rick Homan. 2007. "Strengthening financial sustainability through integration of voluntary counseling and testing services with other reproductive health services," FRONTIERS Final Report. Washington, DC: Population Council. 


\title{
Strengthening Financial Sustainability through Integration of Voluntary Counseling and Testing Services with Other Reproductive Health Services
}

\author{
Rumeli Das ${ }^{1}$, Kaushik Biswas ${ }^{1}$, Pradeep Panda ${ }^{2}$, \\ M.E. Khan ${ }^{2}$, Rick Homan ${ }^{3}$ \\ ${ }^{1}$ Child In Need Institute (CINI), Daulatpur, West Bengal, India \\ ${ }^{2}$ FRONTIERS Program, Population Council, New Delhi, India \\ ${ }^{3}$ FRONTIERS Program, Family Health International, Durham, NC, USA
}

January 2007

This study is made possible by the generous support of the American people through the United States Agency for International Development (USAID) under the terms of Cooperative Agreement Number HRN-A-00-98-00012-00 and Population Council Subagreement number AI05.22A. The contents are the responsibility of the Population Council and do not necessarily reflect the views of USAID or the United States Government. 


\section{EXECUTIVE SUMMARY}

The Child in Need Institute (CINI) operated an HIV/AIDS Voluntary Confidential Counseling and Testing (VCCT) center and a Reproductive Health (RH) clinic at separate locations. Concerns about lack of service coordination as well as cost and revenue considerations led CINI to integrate the two services. CINI conducted an operations research (OR) study to examine the impact of integration on utilization and revenues.

The objective of this study was to examine whether integration of services would yield an increase in clients served and improve the financial position of the program. A monitoring system was established to capture utilization, cost, and revenue data. The utilization analysis focused on determining if more clients received services, and measuring the proportion of clients who received both RH and VCCT services. The financial analysis focused on determining whether the provision of services to a client (separately or together) added more to program costs or to program revenues.

Provision of RH services increased from 12 services per clinic day in the 9 months prior to integration to 25 services per clinic day in the first 9 months post-integration. The corresponding figures for VCCT service provision were 4 services per day prior to integration and 22 services per day subsequent to integration. In addition, on average, 14 of the 37 daily clients ( 38 percent) received both $\mathrm{RH}$ and VCCT services in the post integration period. When registration fees were compared to the variable cost of service provision, there was a small positive contribution margin earned (US\$0.07) indicating that the provision of integrated services added more to program revenues than to program costs.

Integrating services was associated with increased provision of services and improved financial sustainability. A potential confounder for the increase in service volume was the intensive promotion that took place simultaneously with the integration of services. Regardless, due to the reduction in fixed costs post-integration and increased registration fees, the financial sustainability of CINI improved. The study also demonstrates that the capacity of CINI to carry out economic evaluations of their programs was improved as a result of training in economic analysis and operations research. 


\section{TABLE OF CONTENTS}

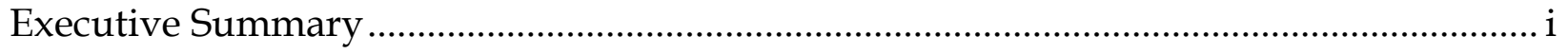

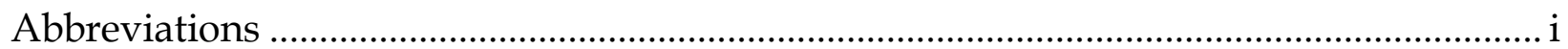

Acknowledgments ..........................................................................................................

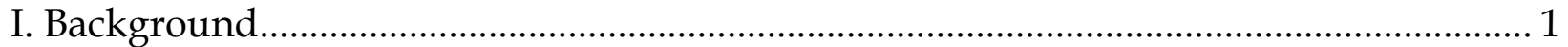

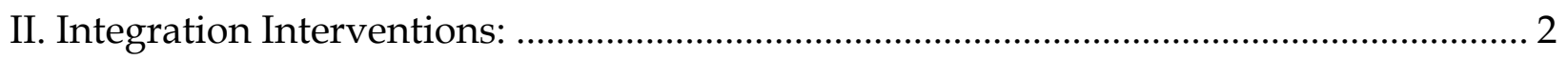

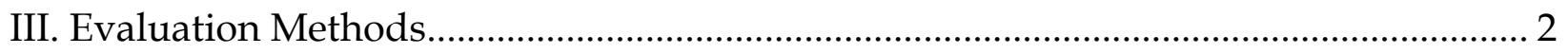

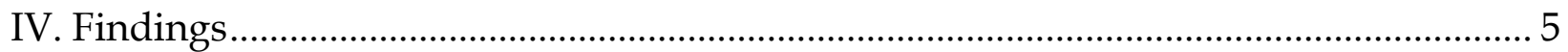

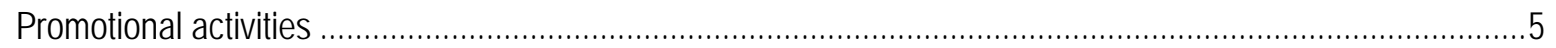

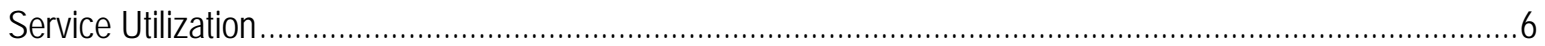

Improved access to services ........................................................................................................

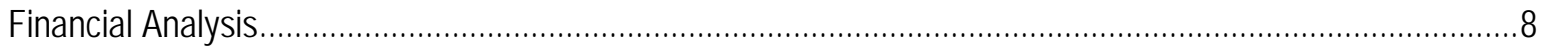

Cost recovery from integrated services ......................................................................................

Contribution margin analysis ...................................................................................................

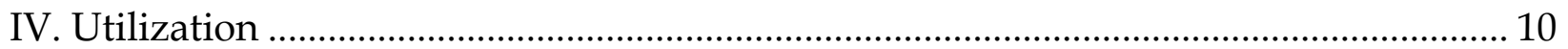

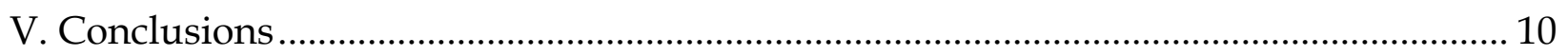

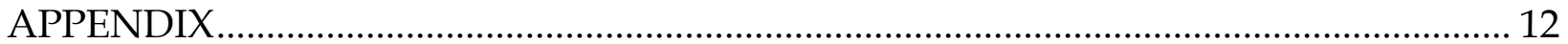

Estimation of cost per service ........................................................................................................12 


\title{
Abbreviations
}

\author{
AIDS ..............Acquired Immune Deficiency Syndrome \\ CINI ...............Child in Need Institute \\ HIV ................Human Immunodeficiency Virus \\ ICDS ...............Integrated Child Development Services \\ M\&E ...............Monitoring and Evaluation \\ OR ................... Operations Research \\ RH .................Reproductive Health \\ RTI .................Reproductive Tract Infection \\ SHG.................Self Help Group \\ STD ................Sexually Transmitted Disease \\ VCCT .............Voluntary Confidential Counseling and Testing \\ WBSACPS .....West Bengal State AIDS Control and Prevention Society
}




\section{ACKNOWLEDGMENTS}

We are thankful to the FRONTIERS Program of the Population Council for having funded this project, and for helping us to build our capacity to conduct financial sustainability research. We are also grateful to Integrated Child Development Services (ICDS), Block I and II for extending every support to carry out the program activities. We also wish to acknowledge the support of the 'Pradhans' of several Gram Panchayats (equivalent to the heads of village councils), as well as the support of all the supervisors and workers of ICDS who helped conduct the study activities. Our sincere thanks go to Dr. M.E. Khan, Regional Associate Director, FRONTIERS Program, Population Council; Dr. Rick Homan, Senior Associate for Health Economics, Family Health International; and Dr. Pradeep Panda, Fellow in Economics, Population Council for providing training, technical support, and guidance to carry out this research project. The outreach workers, monitoring and evaluation officer, data entry operator, and other concerned personnel deserve praise for their tireless efforts to complete the study successfully. Thanks are also due to the other members of CINI-Bandhan, who extended valuable support at different junctures of this program. Finally, thanks are due to Dr. James Foreit of the Population Council, and Dr. Barbara Janowitz and Mr. John Bratt of Family Health International for their extensive review and comments, which considerably improved the report. 


\section{BACKGROUND}

One of the key activities of the FRONTIERS Program of the Population Council is to train and help NGOs build their capacity to use operations research (OR) techniques and financial analysis to make programmatic decisions designed to reduce donor dependency. A regional workshop was held in India in 2004, where three NGOs, one each from Bangladesh, India and Nepal were helped to develop OR proposals that were subsequently funded by FRONTIERS. On-going technical assistance was provided to help the organizations finish the protocols and carry out the research. One of the participants was the Child In Need Institute (CINI) in West Bengal. This report describes the study they undertook.

CINI operated a donor-supported reproductive health $(\mathrm{RH})$ clinic and a physically separate voluntary confidential counseling and testing (VCCT) center with support from the West Bengal State AIDS Control and Prevention Society (WBSACPS). The RH clinic provided curative RTI/STI services, preventive services like family planning, condom distribution and counseling on RTI/HIV risk behaviors. Clients of the RH clinic paid a registration fee of Rs. 20. The VCCT clinic operated 5 days per week and collected a fee of Rs. 10 that was remitted to the Government for the testing of samples. No registration fee was charged to clients attending the VCCT clinic.

Because the services were physically separated, problems with the coordination of service delivery were perceived when counselors or clinicians felt dual service use was indicated. In addition, there were staffing redundancies, as a trained counselor was required in both locations, which increased the fixed cost of service provision. Finally, the lack of a registration fee at the VCCT clinic limited the ability of CINI to generate revenues with which to offset program costs.

Therefore, in June 2005 CINI decided to integrate the two clinics and impose a uniform registration fee of Rs. 20 to all clients. This change was expected to reduce the fixed costs of service delivery, and potentially increase both the volume of services provided and total revenue. The reduction in fixed costs comes from the elimination of a redundant staff member (counselor). Integrating the services improved access to the combination of RH and VCCT services as both services could be provided at a single client visit. The uniform registration fee means that clients that previously were not charged a registration fee (VCCT clients) would now be paying to access services.

Research Questions: The purpose of this study was to examine whether integration of RH and VCCT services increased access to services and improved the financial position of CINI. Specific research questions included:

1. What are the problems for which clients seek services at the integrated clinic?

2. What is the pattern of service utilization (RH only, VCCT only, and both services combined)?

3. What are the total costs and total and average variable costs of providing RH only, VCCT only, and both services to clients at the integrated clinic?

4. What are the total revenues of the integrated clinic by service category (including RH only, VCCT only, and both services combined)? 
5. Does service provision in the integrated clinic yield a positive or negative contribution margin?

\section{INTEGRATION INTERVENTIONS:}

- In June 2005, the VCCT and RH clinics were integrated within the RH clinic on the main CINI campus. The integrated service is offered every Thursday from 8:30 am to 1:30 pm.

- In July 2005, CINI introduced a uniform registration fee of Rs. 22 ( US\$ 0.50) for new clients and Rs. 20 for returning clients. The return visit fee is waived if the client is returning solely for a VCCT result. Otherwise, these fees are fixed whether only one or both services are utilized. In this way there is no financial barrier to using the integrated services. As before, each client who requests HIV/AIDS screening pays an additional Rs. 10 screening fee (which goes directly to the government as the blood testing charge). This fee is not considered part of CINI's revenue as it is a pass-through to the government laboratory.

- Because there was going to be a change in the point of service delivery, the availability of services at the service delivery point, and the fee structure, CINI recruited two outreach workers in July 2005. The outreach workers were expected to hold outreach meetings, distribute posters, and distribute leaflets describing the integrated clinic with information on HIV/AIDS and RH problems to villages within a $20 \mathrm{~km}$ radius of the clinic.

- Finally, a unique registration identification number was introduced in July 2005 so that dual use of services could be measured.

\section{EVALUATION METHODS}

Design: To evaluate the impact of integrating services on access, a simple before and after comparison of service volumes was carried out. The pre-integration study period was September 2004-June 2005. The post-integration period was July 2005-January 2006. A comprehensive monitoring system was put into place to examine the volume of clients served and the utilization of different services at the integrated clinic. Unfortunately, prior to the start of the study, a uniform registration ID was not used by CINI in the two clinics so we were unable to assess the extent to which clients used dual services prior to integration. Therefore changes in the volume of services provided per clinic day will be explored as an indicator of change in the accessibility of services.

In order to assess whether clients were adding more to program revenues or to program costs when accessing services through the integrated clinic, CINI undertook a contribution margin analysis. The contribution margin is the difference between the revenue collected per client and the average variable cost of service provision. This represents the net revenue that can then be used to help offset the fixed costs of service provision. Only when the contribution margin is positive can the program hope to improve its financial sustainability through increased service provision. 
Data collection: Prior to the integration of the clinics in the month of June 2005, the M\&E officer introduced three registers to capture information required for analysis.

- Registration book: This register is used to assign a registration ID to new clients, or record the ID of returning clients. The fee that was collected, depending on whether a new or old client, the service or services used during this visit, and the name of the village where the client lives was recorded in this register.

- Clinical record book: This register has two sections, a personal information section in which the socio-demographic data related to the client are recorded, and a clinical record section. The clinical record section has three parts: in the first part the information on the reproductive health related clinical complaints, clinical findings, diagnosis, and medicines prescribed are recorded; in the second part information related to VCCT services i.e. pretest, test, posttest, and follow up are recorded. And lastly in the third section family planning information is recorded i.e., what mode of FP method the client uses and whether he/she asked for condoms, oral pills, or an IUD which are distributed from the clinic.

- Medicine stock and clinical supplies register: to monitor the use of medicines and supplies for the clients availing the RH service and the supplies used for the clients seeking VCCT service, an initial inventory of those items was performed. Clinic requisition forms were used to document additions to inventory. The total of beginning inventory plus additions less the ending balance yields the quantity of supplies used by the clinic.

Data entry software was developed to capture the data from the registers in computerized form for subsequent analysis using SPSS and Excel.

\section{Dependent variables:}

Service Utilization: CINI was specifically interested in knowing if a client is utilizing one service or multiple services during the same visit. In addition, CINI was interested in knowing the types of RH problems or complaints that clients report when seeking care. These data were captured in the clinic registries at each client visit. Using the common client identifier, data are then linked across registries so that clients who use both services can be identified. Clients were categorized into three groups:

- Those who used RH services only

- Those who used VCCT services only

- Those who used both RH and VCCT services.

This last group includes persons who arrived at the clinic with the intent to receive both services as well as clients who came for one service, and were referred by the provider to the other service if needed, and used the recommended service.

Cost of Services: Total costs of providing services in the integrated clinic were estimated for the entire clinic as well as for the three different service utilization patterns. Depending upon the type of resource, different approaches to cost estimation were used. 
Labor: Clinical and support labor costs were estimated by identifying the total payments to each staff member working in the integrated clinic, the total hours worked by that person across the organization, and the total hours worked by that person in the integrated clinic. The fraction of hours worked in the integrated clinic determines the fraction of total payments to be allocated to the integrated clinic for that person. The annual labor costs were then prorated to represent the 8-month period of this study. Labor costs were allocated to services based upon the relative volume of services that a given type of labor provides or supports.

Supplies and Materials: For joint supplies (supplies and materials shared by multiple clients) CINI purchasing records were used to estimate the cost of cleaning supplies, IEC materials, and office supplies purchased for the integrated clinic. For non-joint supplies (supplies used by a single client) the actual quantity used (from the medicine stock and clinical supplies register) in each service area was multiplied by the appropriate unit cost (from purchasing records) and summed across all items to yield the total non-joint supply costs for a service.

Joint supply costs were allocated to services based upon the relative volume of services provided within the integrated clinic. Since non-joint supplies are directly linked to the type of service provided, these costs were allocated directly. The production of outreach materials was financed through the operations research project and does not represent an on-going financial cost to CINI.

Equipment: An inventory of equipment and instruments in the integrated clinic was performed and for each item an estimated replacement cost and expected useful life was estimated. Taking into account the expected useful life, an 8 percent discount rate was used to annualize the replacement cost for each item. This is then multiplied by the number of units of a particular item and summed across items to obtain an estimated annual cost for equipment and instruments. Annualized costs were then prorated to represent the 8-month period of this study and allocated to specific services proportional to service volume.

Clinic Infrastructure: The annual operating costs for the CINI campus were estimated based upon financial records in the accounting department and then allocated to the integrated clinic based upon share of total campus area occupied. These annual costs were then prorated to represent the 8-month period of this study. Clinic infrastructure costs were then allocated to services in proportion to the volume of services provided.

The cost of outreach activities, equipment and instruments, clinical labor and support labor, and joint supplies were classified as fixed costs because they do not change in response to small changes in the volume of services provided. Non-joint supply costs will change with small changes in the volume of services provided and therefore are classified as variable costs. This distinction between fixed and variable costs will be essential to the contribution margin analysis described below. More details on how costs were estimated, allocated to services, and classified can be found in the Appendix. 
Initially, only the cost of resources for which CINI pays was assessed. However, as part of the financial sustainability analysis, the implications of the withdrawal of the WBSAPCS support are discussed below.

Cost Recovery: Total revenues collected during the study period were computed from the clinic register. By comparing these revenues to the total costs computed above, we can estimate the percent of total costs that are covered through the registration fees. This calculation was also performed by service utilization pattern.

Contribution Margin: CINI used data from the above activities to examine the contribution margin. The contribution margin is computed as the average fee collected for a service minus the average variable cost for the service.

Analyses: For service utilization, CINI examined the number of services delivered per clinic day prior to integration and subsequent to integration. A daily utilization rate was computed for each month since each month had a different number of clinic days due to holidays and variation in the number of Thursdays per month. A simple regression analysis controlling for temporal trend and intervention period was used to test for a significant increase in the use of services over time and whether the trend is different in the post-integration period. Because there was a unique identifier in the post-integration period, the proportion of clients who receive both services in a single visit was also assessed. This is computed as the number of clients using both services divided by the total number of clients served. This measure was not possible for the preintegration period, but an upper limit can be estimated based upon relative service volumes.

For the financial analysis, there is no assessment of the financial performance prior to integration. Fixed costs are known to be lower after integration since the labor costs have been reduced. In addition, revenues will now be higher due to the introduction of uniform registration fees. Both of these factors work together to improve financial performance, however, if service volumes have increased, there will be an increase in variable costs. Therefore the key assessment is whether or not the registration fees are sufficient to offset the variable cost of service provision (contribution margin analysis). The contribution margin represents the amount of service fee revenue that is left over to help offset the fixed costs of service provision. A positive contribution margin indicates that provision of service to the client adds more to total revenues than it adds to total costs. Only if the contribution margin for a service is positive can the clinic hope to offset fixed costs through the provision of services.

\section{FINDINGS}

\section{Promotional activities}

The outreach workers organized approximately three meetings in each of 78 villages reaching an estimated population of 53,000 persons aged 15-49. In the meetings they discussed reproductive health problems, what HIV/AIDS is, how HIV/AIDS is transmitted, and ways of preventing HIV/AIDS. They promoted the integrated clinic and described the services provided in the clinic and the fee structure. Follow-up meetings were organized in different villages. Community 
based meetings of various types ${ }^{1}$ were organized in the target area. Table 1 presents the number of meetings organized by target group, and the average number of attendees per meeting.

Table 1: Number of Outreach Meetings Organized and Average Number of Attendees

\begin{tabular}{|l|c|c|}
\hline \multicolumn{1}{|c|}{ Target Group } & $\begin{array}{c}\text { Number of } \\
\text { Meetings }\end{array}$ & $\begin{array}{c}\text { Average Number } \\
\text { of Attendees } \\
\text { per Meeting }\end{array}$ \\
\hline Community Members & 127 & 40 \\
\hline Adolescent Peer Educators & 27 & 20 \\
\hline Anganwadi Workers \& Helpers & 23 & 15 \\
\hline Self Help Groups (SHG) & 12 & 15 \\
\hline Panchayat members & 8 & 12 \\
\hline Club Members & 10 & 15 \\
\hline Religious Leaders & 3 & 12 \\
\hline ANMs \& Health Workers & 5 & 8 \\
\hline
\end{tabular}

In addition to meetings, five thousand pamphlets with information related to the integrated clinic were distributed. Five hundred posters with information on HIV/AIDS and RH problems, and the ways of preventing them (with CINI identified as an integrated treatment center) were produced. Posters were then distributed to the PHCs, the drop in centers, hospitals, local clubs, Panchayat offices, Integrated Child Development Services (ICDS) centers, and health sub centers. Posters were displayed at the different functions organized during World AIDS week in December 2005, and in the "Health Mela" (fair) organized by CINI in the month of January 2006. Posters were also displayed in other village fairs organized by the local community throughout the months of January and February 2006. In addition, 2,000 leaflets with information on the integrated clinic with a briefing about HIV/AIDS and RH problems, and the CINI clinic identified as a treatment center were produced.

\section{Service Utilization}

\section{Reason for Visit}

The registration book and clinical record book captured information on the problems for which RH services were being sought, and which service(s) was used. The majority of clients coming into the integrated $\mathrm{RH}$ clinic $(69 \%)$ mentioned some type of $\mathrm{RH}$ problem or complaint. It is worth noting that 27 percent of the clients came specifically for VCCT services, while 3.9 percent had no specific RH problem or complaint noted. Of the 69 percent mentioning a single $\mathrm{RH}$ problem or complaint, the majority reported white discharge $(20 \%)$ or menstrual abnormalities (10\%). Vaginal problems (pain, itching, or dryness) (5\%), lower abdominal pain $(3 \%)$, or urination problems $(1 \%)$ are less common but also reported by clients. Almost 20 percent of clients reported multiple problems or complaints.

\footnotetext{
1 These include: panchayat members meetings (local governing body), self-help group meetings, adolescent peer educator meetings, Anganwadi workers and helpers (village level health workers specializing in nutrition for children under 5 and pregnant women), club members meetings and meetings with religious leaders.
} 


\section{Improved access to services}

In Figure 1, the use of RH and VCCT services (average number of services provided per clinic day) is shown for the nine months prior to integration and the first nine months post-integration ${ }^{2}$. Post-integration use of both RH and VCCT services increased and has increased at a faster rate than prior to integration for the VCCT services ${ }^{3}$. In the pre-integration period, the average clinic day included $12 \mathrm{RH}$ encounters and 4 VCCT encounters. Subsequent to integration, the average clinic day included $25 \mathrm{RH}$ encounters and 22 VCCT encounters delivered to 37 clients.

Figure 1: Volume of Services per Clinic Day by Type (Pre \& Post Integration)

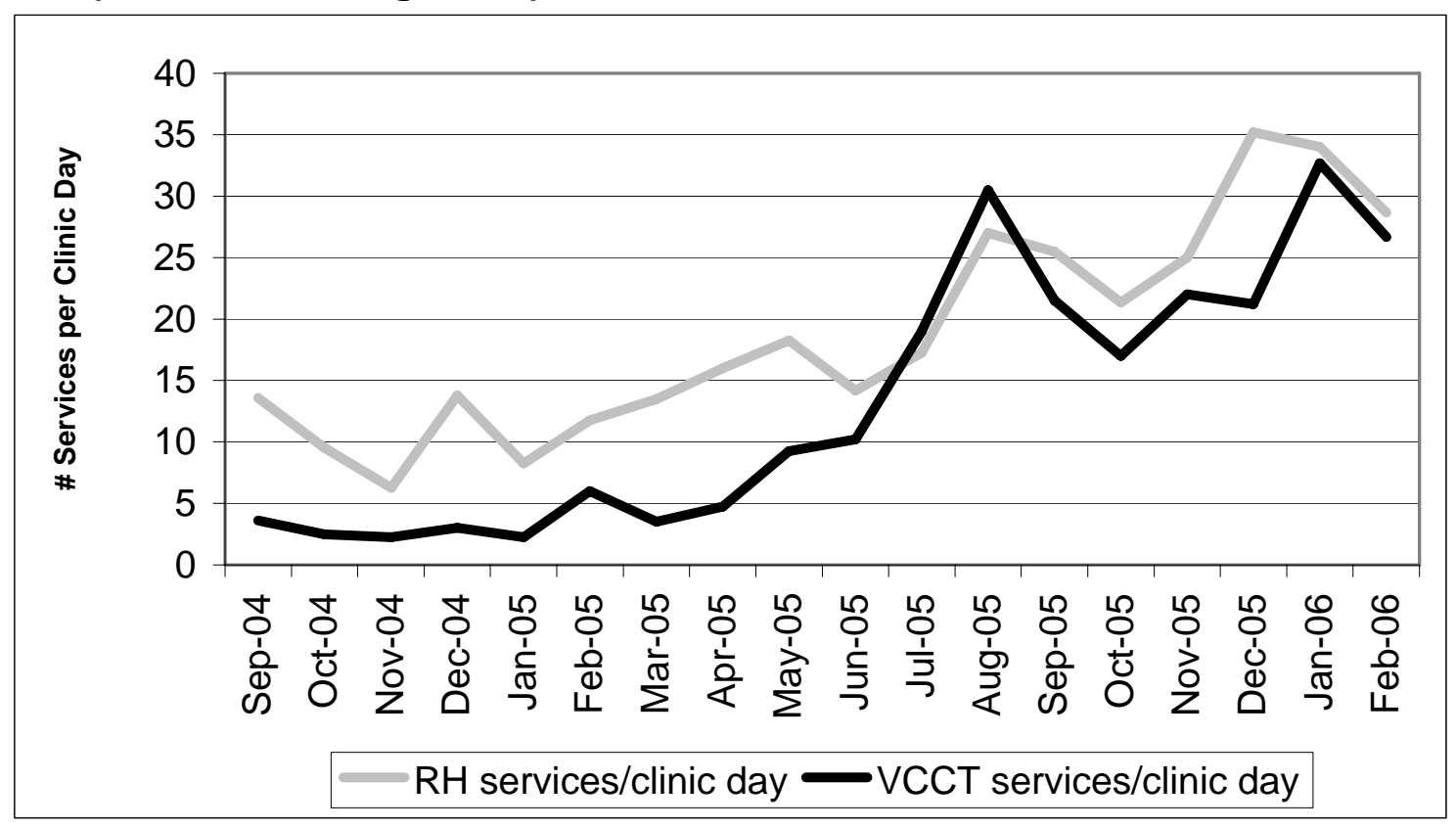

There were some concerns that, after integration, there might be some displacement of $\mathrm{RH}$ clients due to the new structure of providing services. But Figure 2 below clearly indicates that the number of clients accessing service in RH, VCCT and the RH \& VCCT category is continuing to increase during the post integration period. There is also a considerable proportion of clients receiving both RH and VCCT services (on average, 38\% during the post integration period). While we do not have an estimate of dual service use from the pre-integration period, it was likely to be substantially lower due to the inability to access both services during a single visit.

2 Rather than counting clients served per day we look at the volume of services per clinic day since from the pre-integration period we were unable to identify clients who may have received both services due to a lack of a common patient identifier.

A simple linear regression with temporal trend and integration period as explanatory variables indicates a statistically significant increase in the provision of services post integration vs. prior to integration. The linear trend for RH services per day was (beta $=1.454 ; \mathrm{p}=.0012)$ with a statistically insignificant coefficient on integration period (pre vs. post). The linear trend for VCCT services was (beta $=1.030 ; p=.0210)$ with a statistically significant coefficient on integration period (pre vs. post) (beta=8.910; $\mathrm{p}=.0491$ ). 


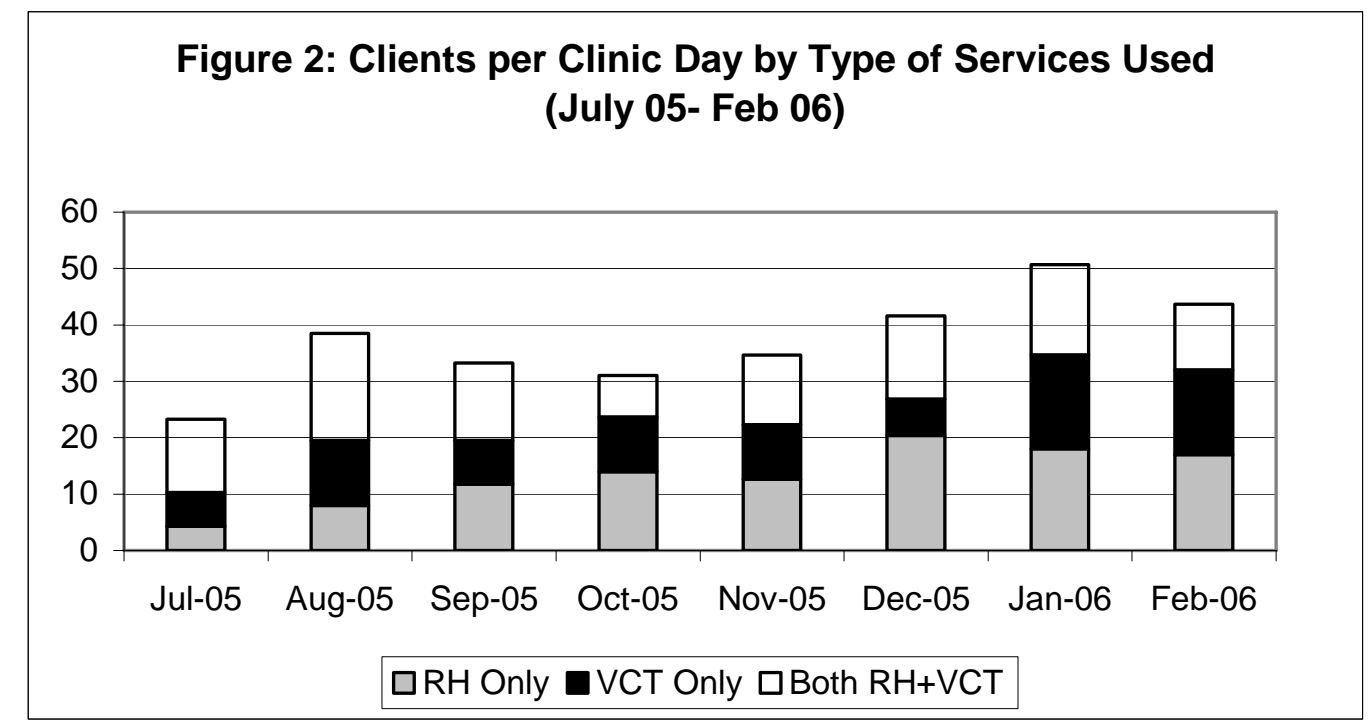

\section{Financial Analysis}

\section{Cost of integrated services}

Table 2 shows the cost incurred for the different service utilization patterns by type of resource. These costs reflect the expenses incurred by CINI to provide services during this study period. The value of resources paid for by the WBSAPCS (some clinical labor and the non-joint supplies for VCCT services) are not reflected in this table but are discussed in the financial sustainability section below.

Table 2: Cost by Service Utilization Pattern (July 05 - Feb 06)

\begin{tabular}{|c|c|c|c|c|}
\hline \multicolumn{1}{|c|}{ Cost Elements } & $\begin{array}{c}\text { Total Visits } \\
\mathbf{( n = 1 , 0 6 8 )}\end{array}$ & $\begin{array}{c}\text { RH Only } \\
\text { Visit } \\
(\mathbf{n = 3 8 3})\end{array}$ & $\begin{array}{c}\text { VCCT Only } \\
\text { Visit } \\
\mathbf{( n = 2 8 6 )}\end{array}$ & $\begin{array}{c}\text { Both RH + VCCT } \\
\text { Visit } \\
(\mathbf{n = 3 9 9 )}\end{array}$ \\
\hline Labor & & & & \\
\hline Clinical Labor & 41,219 & 16,603 & 7,319 & 17,297 \\
\hline Support Labor & 53,699 & 17,553 & 12,507 & 23,639 \\
\hline Supplies \& Materials & & & & 5,123 \\
\hline Joint & 13,714 & 4,918 & 3,672 & 8,312 \\
\hline Non-Joint & 16,290 & 7,979 & 0 & 2,230 \\
\hline Equipment & 4,236 & 1,606 & 399 & 1,026 \\
\hline Clinic Infrastructure & 2,745 & 984 & 735 & $\mathbf{5 7 , 6 2 8}$ \\
\hline Total Cost (Rs.) & $\mathbf{1 3 1 , 9 0 3}$ & $\mathbf{4 9 , 6 4 3}$ & $\mathbf{2 4 , 6 3 3}$ & \\
\hline
\end{tabular}




\section{Cost recovery from integrated services}

The revenues collected by CINI through the registration fees are shown by service utilization pattern in the Table 3 below. Comparing these figures to the previous table it becomes clear that these services are not self-sustaining. Rather CINI will continue to be dependent upon external support for the continued operation of these programs. Overall about 15 percent of program costs are recovered through the registration fees. The remaining 85 percent are financed through other mechanisms.

Table 3: Revenues by Service Utilization Pattern (July 05-Feb 06)

\begin{tabular}{|c|c|c|c|c|}
\hline Service Revenues & $\begin{array}{c}\text { Total Visits } \\
(\mathbf{n = 1 , 0 6 8 )}\end{array}$ & $\begin{array}{c}\text { RH Only } \\
\text { Visit } \\
(\mathbf{n = 3 8 3})\end{array}$ & $\begin{array}{c}\text { VCCT Only } \\
\text { Visit } \\
(\mathbf{n = 2 8 6})\end{array}$ & $\begin{array}{c}\text { Both RH + VCCT } \\
\text { Visit } \\
(\mathbf{n}=\mathbf{3 9 9})\end{array}$ \\
\hline Registration Fees (Rs.) & 19,496 & 8,062 & 2,992 & 8,442 \\
\hline Percentage of Total Costs & 14.8 & 16.2 & 12.1 & 14.6 \\
\hline
\end{tabular}

\section{Contribution margin analysis}

Even though the revenues collected from registration fees (\$440) account for only a small part of the total costs incurred to provide the services, it is important to know whether these revenues are sufficient to cover the variable cost of service delivery. This is the purpose of contribution margin analysis. Table 4 below summarizes the average total cost, average variable cost and the average revenue (fee collected) for each of the service utilization patterns, and overall. The final column shows the contribution margin by service utilization pattern.

Table 4: Contribution Margin by Service Utilization Pattern (July '05 - Feb '06)

\begin{tabular}{|l|c|c|c|c|c|}
\hline $\begin{array}{c}\text { Service } \\
\text { Utilization } \\
\text { Pattern }\end{array}$ & $\begin{array}{c}\text { Total } \\
\text { Visits }\end{array}$ & $\begin{array}{c}\text { Average Total } \\
\text { Cost } \\
\text { (Rs.) }\end{array}$ & $\begin{array}{c}\text { Average } \\
\text { Variable Cost } \\
\text { (Rs.) }\end{array}$ & $\begin{array}{c}\text { Average } \\
\text { Revenue } \\
\text { (Rs.) }\end{array}$ & $\begin{array}{c}\text { Contribution } \\
\text { Margin } \\
\text { (Rs.) }\end{array}$ \\
\hline RH Only & 383 & 129.6 & 20.8 & 21.0 & 0.2 \\
\hline VCCT Only & 286 & 86.1 & $-5^{2}$ & $10.5^{2}$ & 10.5 \\
\hline $\begin{array}{l}\text { Both RH \& } \\
\text { VCCT }\end{array}$ & 399 & 144.4 & 20.8 & 21.2 & 0.4 \\
\hline Total Visits & $\mathbf{1 , 0 6 8}$ & $\mathbf{1 2 3 . 5}$ & $\mathbf{1 5 . 3}$ & $\mathbf{1 8 . 3}$ & $\mathbf{3 . 0}$ \\
\hline
\end{tabular}

1 Average total cost for the VCCT services excludes the costs of supplies for collecting the blood samples (variable cost) and the cost of the counselor and technician (fixed costs). All of these costs are sponsored by the WBSAPCS so no variable costs are incurred by CINI when providing VCCT services.

${ }^{2}$ The average revenue for the VCCT only service is substantially lower than Rs. 20 since clients returning solely for a test result are not charged a registration fee.

Overall, a small positive contribution margin of Rs. 3.0 (\$0.07) per visit was generated during the study period. It is worth noting that the only service pattern that generates a meaningful contribution margin is the provision of VCCT services only. This is the result of the lack of variable costs for this service due to the support from the WBSAPCS. It is worth noting, 
however, that if the WBSAPCS were to stop providing resources to CINI, the same utilization pattern would have had an overall contribution margin of Rs. - 0.6 per visit (or a net loss on each client served). This highlights the importance of continued support from the state AIDS Prevention and Control Society if VCCT services are to remain available.

\section{UTILIZATION}

As a result of participation in this study, CINI is now able to apply these techniques to estimate the cost of other program activities. Specific skills that were transferred to CINI through this capacity building activity include: the estimation of service specific costs, familiarity with cost allocation decision rules applicable to shared resources, and the ability to compute and interpret contribution margins. In addition, they now have an integrated database, which allows them to track client utilization of services across all the registries in the integrated clinic. The methods used in this study will help CINI to formulate a financial sustainability plan for other institutional services, such as the under five clinic and training programs.

\section{CONCLUSIONS}

The study demonstrated the operational and financial feasibility of integrating reproductive health and VCCT services. The observed pattern of service utilization in Figure 1 indicates that subsequent to integration, access to both RH and VCCT services has increased which was the intended effect. However, some of this increase in services is likely to be in response to the extensive outreach efforts that took place during the study period. This highlights the importance of program promotion by NGOs so they can make better use of their fixed resources (labor, equipment, and infrastructure). We cannot disentangle the effects of marketing from the increase in utilization due to improved access to dual service use. It is likely that the outreach activities are responsible for getting more people through the door in the post-integration period, but some of the increase in dual use is probably due to interaction with providers who perceive a need to use both services and convince clients that came seeking one or the other service to use both. Whereas prior to integration there was concern that clients for whom both services were indicated may not be receiving services, in the post-integration period we see that 37 percent of clients receive both services during a visit. This dual use rises to between 53 and 67 percent among clients reporting problems suggestive of RTI/STDs. By making both services available in a single visit, an important potential barrier to utilization has been removed.

In addition to increasing utilization, integrated services were able to yield a small positive contribution margin. Even when both services were provided under a single registration fee, the registration fee was just sufficient to offset the additional cost of serving the client. This means that continued provision of integrated services will not be financially detrimental to CINI under the current set-up. However, the integrated clinic cannot be financially independent at current fee levels as these small margins are insufficient to cover the fixed cost of operating the clinic (such as the labor costs for the clinic). Continued cross subsidization from other activities of the institute or direct donor support will be needed to continue clinic operations. 
This project has illustrated some of the issues facing programs that seek to integrate family planning/reproductive health with HIV services and in a sustainable manner in developing countries. While donors/governments will sometimes cover the variable costs of service provision, less often is there support for the fixed costs required for the delivery of services (labor, equipment, and infrastructure). Often, as a condition of the donor or government support, the NGO is restricted in its ability to raise revenues from these services and therefore some other revenue generating activity is required to subsidize the FP/RH or VCT services. Unless the NGO is permitted to charge a fee sufficient to cover at least the variable costs of service provision, each additional client served will increase rather than decrease external dependency.

The study demonstrates the feasibility of building the capacity of NGOs to use operations research for financial decision-making. CINI has been able to use the acquired economic evaluation skills to make evidence-based decisions regarding service delivery and promotion. 


\section{APPENDIX}

\section{Estimation of cost per service}

\begin{tabular}{|c|c|c|c|}
\hline Cost Element & Data Sources & Allocation Rule & $\begin{array}{c}\text { Fixed vs. } \\
\text { Variable }\end{array}$ \\
\hline Clinical Labor & $\begin{array}{ll}\text { - Accounts } \\
\text { Department }\end{array}$ & $\begin{array}{l}\text { Allocated to RH clinic } \\
\text { proportional to hours } \\
\text { worked. } \\
\text { - Allocated to services } \\
\text { based upon relative } \\
\text { volume of services. }\end{array}$ & - Fixed \\
\hline Support Labor & $\begin{array}{ll}\text { - } & \text { Accounts } \\
\text { Department }\end{array}$ & $\begin{array}{l}\text { Allocated to RH clinic } \\
\text { proportional to hours } \\
\text { worked } \\
\text { Allocated to services } \\
\text { based upon relative } \\
\text { volume of services. }\end{array}$ & - Fixed \\
\hline Equipment & $\begin{array}{l}\text { - } \quad \text { Physical inventory of } \\
\text { RH clinic. } \\
\text { - Replacement cost } \\
\text { from accounts } \\
\text { department. }\end{array}$ & $\begin{array}{l}\text { Allocated to services } \\
\text { based upon physical } \\
\text { location or proportional } \\
\text { to relative volume of } \\
\text { services if shared } \\
\text { across services. }\end{array}$ & - Fixed \\
\hline Joint supplies & $\begin{array}{l}\text { Purchasing log from } \\
\text { accounts department } \\
\text { for IEC materials, } \\
\text { registers, cleaning } \\
\text { supplies. } \\
\end{array}$ & $\begin{array}{l}\text { Allocated to services } \\
\text { based upon relative } \\
\text { volume of services. }\end{array}$ & - Fixed \\
\hline $\begin{array}{l}\text { Non joint } \\
\text { supplies }\end{array}$ & $\begin{array}{l}\text { Medical stock \& } \\
\text { clinical supplies } \\
\text { register used to } \\
\text { document records. } \\
\text { Accounts department } \\
\text { records used to } \\
\text { assign value. }\end{array}$ & $\begin{array}{l}\text { Allocated to services } \\
\text { based upon actual } \\
\text { usage in medical stock } \\
\text { \& clinical supplies } \\
\text { register }\end{array}$ & - Variable \\
\hline $\begin{array}{l}\text { Clinic } \\
\text { Infrastructure }\end{array}$ & $\begin{array}{l}\text { Accounts department } \\
\text { provided the annual } \\
\text { operational cost for } \\
\text { CINI campus } \\
\text { (utilities, insurance, } \\
\text { administration) }\end{array}$ & $\begin{array}{l}\text { Allocated to RH clinic } \\
\text { based upon share of } \\
\text { total square feet. } \\
\text { Allocated to services } \\
\text { based upon relative } \\
\text { volume of services. }\end{array}$ & - Fixed \\
\hline
\end{tabular}

